\title{
Unroofing Technique for Endoscopic Resection of a Large Colonic Lipoma
}

\author{
Kiichi Sugimoto $^{\mathrm{a}}$ Koichi Sato $^{\mathrm{a}}$ Hiroshi Maekawa $^{\mathrm{a}}$ \\ Mutsumi Sakurada ${ }^{a}$ Hajime Orita $^{a}$ Tomoaki Ito $^{a}$ \\ Masayuki Saita $^{a}$ Masanori lkota $^{a}$ Yuko Yoshida $^{a}$ \\ Miki Yamanob
}

Departments of ${ }^{\mathrm{a}}$ Surgery and ${ }^{\mathrm{b}}$ Pathology, Juntendo University Shizuoka

Hospital, Izunokuni, Japan

\section{Key Words}

Bowel perforation $\cdot$ Colonic lipoma $\cdot$ Endoscopic resection $\cdot$ Morbidity $\cdot$ Unroofing technique

\begin{abstract}
A 77-year-old man presented with repeated episodes of melena. He had a medical history of hypertension, atrial fibrillation and cardiogenic brain infarction and took medications, i.e. an antiplatelet agent. Laboratory data revealed iron deficiency anemia. Colonoscopy revealed a yellowish smooth submucosal tumor, $50 \mathrm{~mm}$ in diameter, on the Bauhin valve. The lesion was soft and compressible. The overlying mucosa was erosive. CT scan showed a uniform mass with very low density in the ascending colon, corresponding to the above-detected lesion. The clinical diagnosis of colonic lipoma was established. Using a $25 \mathrm{~mm}$ electrocautery snare (Olympus, Tokyo, Japan), we transected the upper portion of the mass to unroof the lesion. The mucosa layer was thick and hard. Fat tissue was observed extruding from the cut surface, consistent with the diagnostic hypothesis. After dissecting the overlying mucosa on the anal side by means of an IT knife (Olympus) in order to completely extrude the mass, the fat tissue was further exposed. It took about $26 \mathrm{~min}$ to perform the whole procedure. There were no procedure-related complications. Macroscopically, the resected lesion was a yellow solid tumor, $1.6 \times 1.5 \times 0.7 \mathrm{~cm}$ in diameter. Histopathologic examination of the excised specimen confirmed the diagnosis of a lipoma. The clinical course was uneventful. A follow-up endoscopy 1 month later showed a scarred mucosa at the resection site. Similarly, a follow-up CT scan 2 months later revealed no evidence of residual lipoma. The unroofing technique is safe, easy and suitable for the treatment of large lipomas.
\end{abstract}




\section{Introduction}

Colonic lipomas are benign, slow-growing mesenchymal neoplasms of the large intestine [1]. Among the benign neoplasms of the colon, they are second only in frequency to adenomatous polyps [2]. Therefore, it may be expected that the chance diagnosis of a colonic lipoma discovered either incidentally during screening or when investigating a symptomatic patient will increase with the widespread use of colonoscopy. The management of colonic lipomas is controversial because their natural history is not fully understood. Although small colonic lipomas are asymptomatic, most large lipomas are accompanied by symptoms such as abdominal pain, bleeding or constipation [1]. There are several reports of the safe electrosurgical removal of colonic lipomas [3, 4]. However, removal of lipomas $2 \mathrm{~cm}$ in size or larger has been associated with a greater risk of perforation [3-5]. In recent advances in endoscopic therapy, the endoscopic submucosal dissection (ESD) method increases the rate of complete en bloc resection of large gastric mucosal cancers with large mucosal defect; however, it is technically difficult and accompanied by a high risk of complications [6]. Although ESD also reduces the local recurrence rate, a long procedure time and a high incidence of bleeding and perforation remain a problems [6]. Herein, we report the case of a large colonic lipoma causing gastrointestinal bleeding, which was removed using an endoscopic unroofing technique.

\section{Case Report}

A 77-year-old man presented with repeated episodes of melena. He had a medical history of hypertension, atrial fibrillation and cardiogenic brain infarction and took medications, i.e. an antiplatelet agent. The physical examination findings revealed no tenderness at the abdomen and left hemiplegia that was a consequence of brain infarction. Laboratory tests showed: erythrocyte count $324 \times 10^{4} / \mathrm{mm}^{3}$ (normal 410-530 × 104/ $\mathrm{mm}^{3}$ ), hemoglobin $11.3 \mathrm{~g} / \mathrm{dl}$ (normal $14-18 \mathrm{~g} / \mathrm{dl}$ ), leukocyte count $4,500 / \mathrm{mm}^{3}$ (normal $4,000-8,000 / \mathrm{mm}^{3}$ ), platelet count $15.7 \times 10^{4} / \mathrm{mm}^{3}$ (normal $15-40 \times 10^{4} / \mathrm{mm}^{3}$ ), serum total protein $6.5 \mathrm{~g} / \mathrm{dl}$ (normal 6.5-8.0 g/dl), total bilirubin $0.6 \mathrm{mg} / \mathrm{dl}$ (normal 0.2-1.0 mg/dl), aspartate aminotransferase $16 \mathrm{IU} / \mathrm{l}$ (normal 10-40 IU/l), alanine aminotransferase $14 \mathrm{IU} / \mathrm{l}$ (normal 5-40 IU/l), alkaline phosphatase 314 IU/l (normal 115-360 IU/l), $\gamma$-glutamyl transpeptidase $22 \mathrm{IU} / \mathrm{l}$ (normal 10-60 IU/l), blood urea nitrogen $15.4 \mathrm{mg} / \mathrm{dl}$ (normal $8.0-22.0 \mathrm{mg} / \mathrm{dl}$ ), creatinine $1.0 \mathrm{mg} / \mathrm{dl}$ (normal $0.4-1.2 \mathrm{mg} / \mathrm{dl}$ ), and c-reactive protein $0.3 \mathrm{mg} / \mathrm{dl}$ (normal 0-0.3 mg/dl). Upper gastrointestinal endoscopic findings were unremarkable. Colonoscopy revealed a yellowish smooth submucosal tumor, $50 \mathrm{~mm}$ in diameter, on the Bauhin valve (fig. 1a). The lesion was soft and compressible. The overlying mucosa was erosive (fig. 1b). Barium enema showed an oval-shaped filling defect in the ascending colon. CT scan showed a uniform mass with very low density in the ascending colon, corresponding to the above-detected lesion (fig. 1c). The clinical diagnosis of colonic lipoma was established based on the above findings.

Small bowel disease could not be ruled out as a cause of the gastrointestinal bleeding. However, the patient did not undergo small intestinal endoscopy because he was of advanced age and exhibited the sequelae of brain infarction. Since the overlying mucosa was erosive, this lipoma was considered to be the bleeding source of his melena. It was impossible to conduct endoscopic mucosal resection or ESD because this lesion was broad-based and it was difficult to completely distinguish its base. Moreover, laparoscopy-assisted colectomy was considered. However, because there were risks of postoperative morbidity due to poor general status, it was thought that a less invasive therapy was desirable. The patient was informed of the increased risk of perforation and bleeding during the endoscopic unroofing technique and consent was obtained.

Using a $25 \mathrm{~mm}$ electrocautery snare (Olympus, Tokyo, Japan), we transected the upper portion of the mass to unroof the lesion ( $\underline{\text { fig. } 2}$ a). The mucosa layer was thick and hard. Fat tissue was observed extruding from the cut surface, consistent with the diagnostic hypothesis. After dissecting 
the overlying mucosa on the anal side by means of an IT knife (Olympus) in order to completely extrude the mass, the fat tissue was further exposed (fig. 2b). It took about 26 min to perform the whole procedure. There were no procedure-related complications. Macroscopically, the resected lesion was a yellow solid tumor, $1.6 \times 1.5 \times 0.7 \mathrm{~cm}$ in diameter (fig. $2 \mathrm{c}$ ). Histopathologic examination of the excised specimen confirmed the diagnosis of a lipoma (fig. $2 \mathrm{~d}$ ).

The clinical course was uneventful. Oral intake was resumed on the 8th day after endoscopic treatment and the patient was discharged on the 15th day. After he started to take his oral antiplatelet agent again on the 23rd day, no anemia was evident. A follow-up endoscopy 1 month later showed a scarred mucosa at the resection site (fig. $3 \mathrm{a}$ ). Similarly, a follow-up CT scan 2 months later revealed no evidence of residual lipoma (fig. 3b).

\section{Discussion}

Mayo et al. [7] reported that lipoma occurred in $4 \%$ of 4,000 cases of benign neoplasm of the digestive tract that were treated surgically, and that $64 \%$ of them occurred in the colon and rectum. Colonic lipomas are basically benign and the potential of malignancy is extremely low [8]. Lipomas $<2 \mathrm{~cm}$ are usually asymptomatic, whereas $75 \%$ of patients with lesions $>4 \mathrm{~cm}$ exhibit symptoms [9]. Many therapeutic interventions have been attempted in the treatment of symptomatic colonic lipoma, and have varied from hemicolectomy to segmental resection and local excision [10]. With the advancement of colonoscopy, endoscopic cautery snare resection of colonic lipomas has become popular and has been proven to be a safe therapeutic method, especially for small lesions [11]. However, some studies have demonstrated that removal of lipomas $\geq 2 \mathrm{~cm}$ in diameter is associated with a greater risk of perforation [12]. Therefore, some authors have developed novel techniques. Kim et al. [11] performed endoscopic removal of lipomas with a maximum diameter of $3.8 \mathrm{~cm}$, assisted by the injection of saline solution with or without epinephrine into the submucosa beneath the lesion, with no complications. The feasibility of slow mechanical transection of a large colonic lipoma $4 \mathrm{~cm}$ in diameter with an endoloop ligation technique was also demonstrated by Raju and Gomez [12]. In recent years, some authors have reported an unroofing technique [13, 14]. Large lipomas are also successfully managed by the unroofing technique that only cuts off the upper half of the lipoma, thus preventing perforation [15]. The adipose tissue rapidly exudes from the cut surface, resulting in a scarred mucosa without any residual lipoma after elimination of the remaining adipose tissue [14]. Endoscopic removal with tumor-free margins is not necessary due to the benign nature of lipomas. The unroofing technique allows histological confirmation and treatment with minimum mucosal injury. ESD could be dangerous and requires advanced endoscopic skills when performed within the thin-walled colonic lumen [14]. In this case, it was difficult to identify all of the details of the broad base of this lesion because it was too large. In addition, the patient had a medical history of brain infarction. Therefore, we considered that the patient was not suitable for ESD, which might be dangerous and time-consuming, and planned to perform the unroofing technique. Follow-up endoscopy and CT scan more than 1 month later revealed no evidence of residual lipoma, and he was able to start taking an oral antiplatelet agent again.

For the reasons stated above, we are convinced that the unroofing technique is safe, easy and suitable for the treatment of large lipomas, and is especially useful for high-risk cases with poor general condition. 


\begin{tabular}{r|l|l|l}
$\begin{array}{r}\text { Case Reports in } \\
\text { Gastroenterology }\end{array}$ & $\begin{array}{l}\text { Case Rep Gastroenterol 2012;6:557-562 } \\
\text { DOI: 10.1159/000342350 }\end{array}$ & $\begin{array}{l}\text { Published online: } \\
\text { August 23, 2012 }\end{array}$ & $\begin{array}{l}\text { @ 2012 S. Karger AG, Basel } \\
\text { ISSN 1662-0631 } \\
\text { www.karger.com/crg }\end{array}$ \\
\hline
\end{tabular}

\section{Disclosure Statement}

The authors declare no conflict of interests for this article.
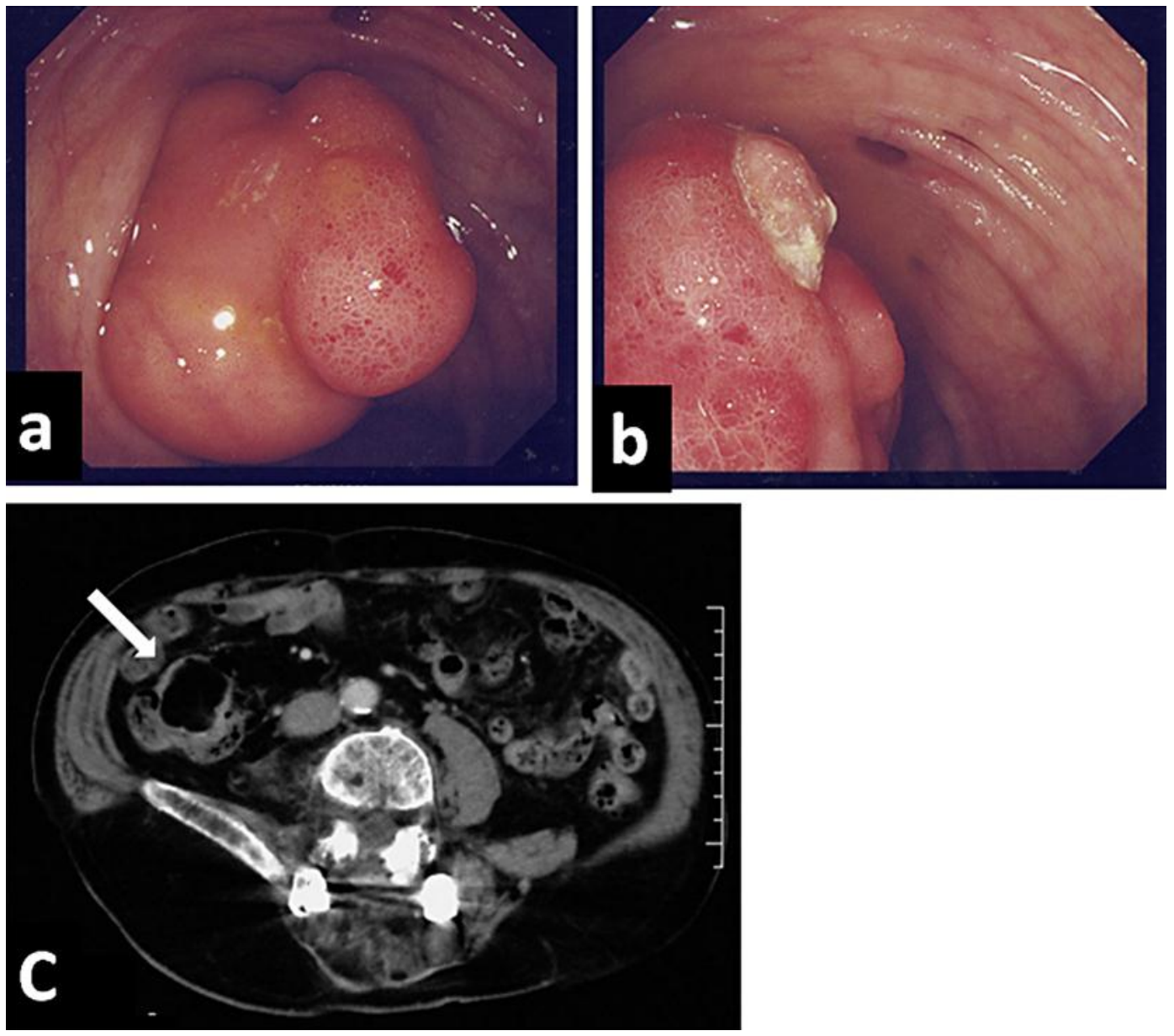

Fig. 1. a Colonoscopy revealed a yellowish smooth submucosal tumor, $50 \mathrm{~mm}$ in diameter, on the Bauhin valve. $\mathbf{b}$ The overlying mucosa was erosive. $\mathbf{c}$ CT scan showed a uniform mass with very low density in the ascending colon, corresponding to the above-detected lesion (arrow). 


\begin{tabular}{r|l|l|l} 
Case Reports in & $\begin{array}{l}\text { Case Rep Gastroenterol 2012;6:557-562 } \\
\text { DOI: 10.1159/000342350 }\end{array}$ & $\begin{array}{l}\text { Published online: } \\
\text { August 23, 2012 }\end{array}$ & $\begin{array}{l}\text { @ 2012 S. Karger AG, Basel } \\
\text { ISSN 1662-0631 } \\
\text { www.karger.com/crg }\end{array}$ \\
\hline
\end{tabular}
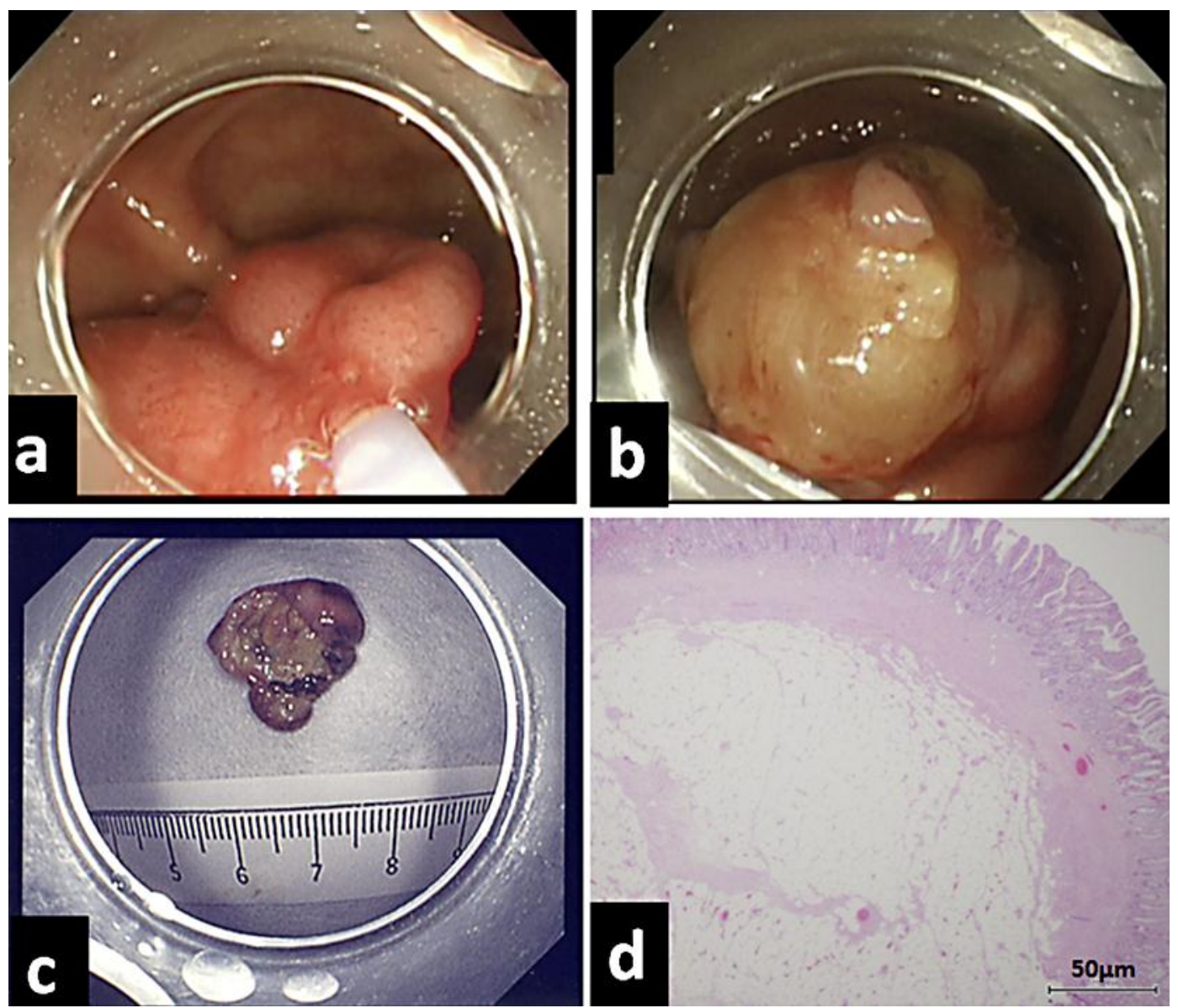

Fig. 2. a Using a $25 \mathrm{~mm}$ electrocautery snare (Olympus), we transected the upper portion of the mass to unroof the lesion. $\mathbf{b}$ After dissecting the overlying mucosa on the anal side in order to completely extrude the mass, the fat tissue was further exposed. c Macroscopically, the resected lesion was a yellow solid tumor, $1.6 \times 1.5 \times 0.7 \mathrm{~cm}$ in diameter. $\mathbf{d}$ Histopathologic examination of the excised specimen confirmed the diagnosis of a lipoma (HE staining).
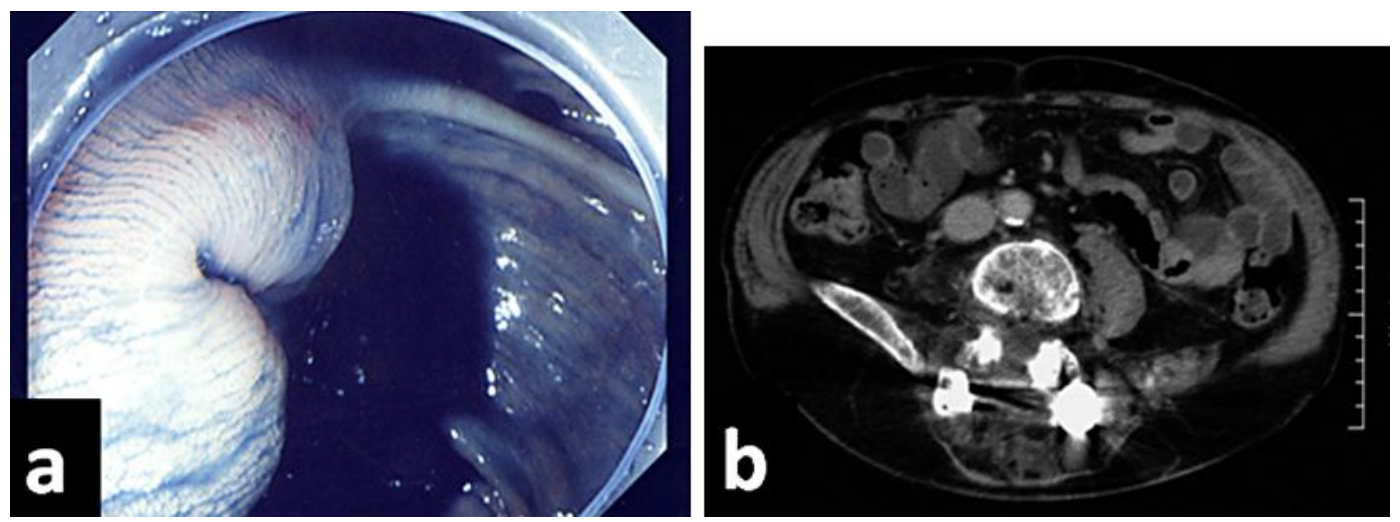

Fig. 3. a A follow-up endoscopy 1 month later showed a scarred mucosa at the resection site. b A follow-up CT scan 2 months later revealed no evidence of residual lipoma. 


\section{References}

1 Chung YF, Ho YH, Nyam DC, Leong AF, Seow-Choen F: Management of colonic lipomas. Aust N Z J Surg 1998;68:133-135.

2 Long GC, Dockerty MB, Waugh JM: Lipoma of the colon. Surg Clin North Am 1949;29:1233-1243.

-3 Creasy TS, Baker AR, Talbot IC, Veitch PS: Symptomatic submucosal lipoma of the large bowel. Br J Surg 1987;74:984-986.

4 Bar-Meir S, Halla A, Baratz M: Endoscopic removal of colonic lipoma. Endoscopy 1981;13:135-136.

5 Pfeil SA, Weaver MG, Abdul-Karim FW, Yang P: Colonic lipomas: outcome of endoscopic removal. Gastrointest Endosc 1990;36:435-438.

-6 Tanaka S, Oka S, Kaneko I, Hirata M, Mouri R, Kanao H, Yoshida S, Chayama K: Endoscopic submucosal dissection for colorectal neoplasia: possibility of standardization. Gastrointest Endosc 2007;66:100-107.

7 Mayo CW, Pagtanulunan RJ, Brown DJ: Lipoma of the alimentary tract. Surgery 1963;53:598-603.

-8 Rogy MA, Mirza D, Berlakovich G, Winkelbauer F, Rauhs R: Submucous large-bowel lipomas presentation and management. An 18-year study. Eur J Surg 1991;157:51-55.

-9 Kitamura K, Kitagawa S, Mori M, Haraguchi Y: Endoscopic correction of intussusception and removal of a colonic lipoma. Gastrointest Endosc 1990;36:509-511.

10 Jiang L, Jiang LS, Li FY, Ye H, Li N, Cheng NS, Zhou Y: Giant submucosal lipoma located in the descending colon: a case report and review of the literature. World J Gastroenterol 2007;13:5664-5667.

11 Kim CY, Bandres D, Tio TL, Benjamin SB, Al-Kawas FH: Endoscopic removal of large colonic lipomas. Gastrointest Endosc 2002;55:929-931.

12 Raju GS, Gomez G: Endoloop ligation of a large colonic lipoma: a novel technique. Gastrointest Endosc 2005;62:988-990.

13 Morimoto T, Fu KI, Konuma H, Izumi Y, Matsuyama S, Ogura K, Miyazaki A, Watanabe S: Peeling a giant ileal lipoma with endoscopic unroofing and submucosal dissection. World J Gastroenterol 2010;16: 1676-1679.

14 Matsushita M, Danbara N, Kawamata S, Omiya M, Okazaki K: Endoscopic removal of large colonic lipomas: difficult submucosal dissection or easy snare unroofing? Endoscopy 2009;41:475.

15 Huang WH, Peng CY, Yu CJ, Chou JW, Feng CL: Endoloop-assisted unroofing for the treatment of symptomatic duodenal lipomas. Gastrointest Endosc 2008;68:1234-1236. 